\title{
Cribriform and intraductal prostate cancer are associated with increased genomic instability and distinct genomic alterations

René Böttcher ${ }^{1 \dagger}$, Charlotte F. Kweldam ${ }^{2 \dagger}$, Julie Livingstone ${ }^{3}$, Emilie Lalonde ${ }^{3,4}$, Takafumi N. Yamaguchi ${ }^{3}$, Vincent Huang ${ }^{3}$, Fouad Yousif ${ }^{3}$, Michael Fraser ${ }^{5}$, Robert G. Bristow ${ }^{4,5,6}$, Theodorus van der Kwast ${ }^{7}$, Paul C. Boutros ${ }^{3,4,8 \dagger}$, Guido Jenster ${ }^{1 \dagger}$ and Geert J. L. H. van Leenders ${ }^{2^{*}+}$

\begin{abstract}
Background: Invasive cribriform and intraductal carcinoma (CR/IDC) is associated with adverse outcome of prostate cancer patients. The aim of this study was to determine the molecular aberrations associated with CR/IDC in primary prostate cancer, focusing on genomic instability and somatic copy number alterations (CNA).

Methods: Whole-slide images of The Cancer Genome Atlas Project (TCGA, N=260) and the Canadian Prostate Cancer Genome Network (CPC-GENE, N = 199) radical prostatectomy datasets were reviewed for Gleason score (GS) and presence of CR/IDC. Genomic instability was assessed by calculating the percentage of genome altered (PGA). Somatic copy number alterations (CNA) were determined using Fisher-Boschloo tests and logistic regression. Primary analysis were performed on TCGA $(N=260)$ as discovery and CPC-GENE $(N=199)$ as validation set.

Results: CR/IDC growth was present in 80/260 (31\%) TCGA and 76/199 (38\%) CPC-GENE cases. Patients with CR/IDC and $\geq$ GS 7 had significantly higher PGA than men without this pattern in both TCGA (2.2 fold; $p=0.0003)$ and CPC-GENE (1.7 fold; $p=0.004$ ) cohorts. CR/IDC growth was associated with deletions of 8p, 16q, 10q23, 13q22, $17 p 13,21 q 22$, and amplification of 8q24. CNAs comprised a total of 1299 gene deletions and 369 amplifications in the TCGA dataset, of which 474 and 328 events were independently validated, respectively. Several of the affected genes were known to be associated with aggressive prostate cancer such as loss of PTEN, CDH1, BCAR1 and gain of MYC. Point mutations in TP53, SPOP and FOXA1were also associated with CR/IDC, but occurred less frequently than CNAs.
\end{abstract}

Conclusions: CR/IDC growth is associated with increased genomic instability clustering to genetic regions involved in aggressive prostate cancer. Therefore, CR/IDC is a pathologic substrate for progressive molecular tumour derangement.

Keywords: Cribriform, Intraductal carcinoma, Prostate cancer, Copy number alteration, Aggressive disease, Genomic instability

\section{Background}

Prostate cancer is heterogeneous regarding its pathologic features, genetic background and clinical outcome. Clinicaldecision making mostly depends upon serum Prostate Specific Antigen (PSA) level, clinical tumour stage, and pathologic biopsy Gleason score (GS) - a grading system based on architectural tumour patterns [1]. While patients

\footnotetext{
*Correspondence: g.vanleenders@erasmusmc.nl

${ }^{\dagger}$ Equal contributors

${ }^{2}$ Department of Pathology, Erasmus University Medical Center, Josephine Nefkens Institute building, Be-222, P.O. Box 2040, Rotterdam 3000 CA, The Netherlands

Full list of author information is available at the end of the article
}

with the lowest GS $\leq 6$ (WHO/ISUP group 1) have an excellent patient outcome, those with the highest GS 9-10 (WHO/ISUP group 5) have the worst $[1,2]$. The clinical outcome of GS $3+4=7$ (WHO/ISUP group 2) prostate cancer patients is variable. Improving risk assessment in this subgroup of patients is of clinical relevance as biopsy GS $3+4=7$ is an important threshold for active treatment. Recent studies have indicated that, among Gleason grade 4 growth patterns, cribriform growth is associated with worse clinical outcome [3-6].

In recent years the clinical relevance of intraductal carcinoma of the prostate (IDC) - a malignant epithelial 
proliferation filling and extending pre-existent glands has been acknowledged. Although not included in the Gleason grading system, IDC has been associated with high GS, advanced tumour stage, biochemical relapse and distant metastasis [7-12]. IDC often mimics invasive cribriform carcinoma, requiring basal cell immunohistochemistry for their distinction. Recently, our group has shown that patients with cribriform and/or intraductal carcinoma (CR/IDC), have significantly worse diseasespecific survival probabilities than those without, regardless of GS [13]. Furthermore, patients with focal CR/IDC have similar outcome as men with extensive CR/IDC, indicating that the mere presence of this growth pattern is an adverse feature [13, 14].

Although the number of mutational events in prostate cancer is relatively low, copy number alterations (CNAs) are significantly more frequent [15-24]. Several studies have developed molecular prognostic signatures, showing that indolent tumours have relatively few CNAs in contrast to large-scale CNAs in highgrade or metastatic tumours $[16,17,25,26]$. However, both the intra- and inter-tumour heterogeneity pose significant challenges for personalizing treatment in patients with prostate cancer [27-29]. For instance, GS 7 prostate cancers harbour a wide range of CNA burden varying between $<1 \%$ to $50 \%$ [26].

Since presence of CR/IDC growth pattern is an independent, adverse clinico-pathologic parameter, we hypothesize that CR/IDC represents a morphological substrate of genomic alterations associated with aggressive disease [13]. The objective of this study was to determine the CNAs and single nucleotide variants (SNVs) associated with CR/IDC using bioinformatics analyses of datasets from The Cancer Genome Atlas Project (TCGA) and the Canadian Prostate Cancer Genome Network (CPC-GENE).

\section{Methods}

\section{Pathological review}

Via online access (http://cancer.digitalslidearchive.net) and mScope Portal (Aurora Interactive, Montréal, Canada) three investigators with expertise in urogenital pathology (C.K., Th.v.d.K., and G.v.L.) reviewed available whole-slide images of frozen sections of both TCGA $(n=260)$ and CPC-GENE $(n=199)$ cohorts. Both cohorts contained radical prostatectomy specimens without prior hormonal or radiation therapy. Each slide was reviewed for GS, tumour percentage and percentage CR/IDC. Percentage CR/IDC was defined as estimated number of CR/IDC tumour cells divided by the total number of cells present in the tissue slice. Since invasive cribriform and IDC-P were morphologically indistinguishable, they were not scored individually [13].

\section{Somatic copy number alterations}

All statistical analyses were performed in the statistical programming language $\mathrm{R}$ v3.2.1 and all genomic coordinates in this manuscript are based on the latest hg19 genome build. Gene-wise $\log _{2}$ ratios for revised TCGA PRAD samples (based on Affymetrix SNP 6.0 arrays) were retrieved via the TCGA-Assembler R-package [30]. To obtain discrete values, gains or deletions of genetic regions were called if a sample's copy number exceeded the threshold of $\pm \log _{2}(1.5 / 2)$. Similarly, a gene-by-sample matrix was obtained for all revised CPC-GENE samples based on Affymetrix OncoScan arrays as described in [17]. Percent genome altered (PGA) was calculated for both the whole genome (excluding chrX and chrY) as described in [17] and separately for individual chromosome arms. For chromosome arms, separate PGAs for amplifications and deletions were obtained by dividing the number of bases affected by a deletion/amplification by the number of bases of the respective chromosome arm, taking into account only one DNA strand as PGA does not account for the strand of CNAs. For all values, a Wilcoxon-MannWhitney test was performed to test for significant differences between GS categories.

For identifying CR/IDC-associated events, the TCGA cohort was used as discovery set and the CPC-GENE cohort was used for validation. We initially used all CR/ IDC positive samples for our analyses, but subsequently limited the CR/IDC group to cases with at least $30 \%$ to account for possible signal losses due to dilution effects caused by non-CR/IDC tissue without CNAs. This dilution effect can be envisioned assuming that CNAs of interest are $\mathrm{CR} / \mathrm{IDC}$-associated and corresponding signals therefore mainly originate from the CR/IDC compartment of the tumour. Surrounding non-CR/IDC tissue hence does not harbor these CNAs and only contributes to background signal leading to a reduced signal-to-noise ratio when trying to detect the CNAs in a mixture of both tissues. Prior to analysis, duplicated gene names, known read-throughs, genes on nonrandom/haplotype chromosomes, as well as genes in pseudoautosomal regions and with missing data were removed. After these filtering steps, 22,350 and 22,420 genes remained for analysis of the TCGA and CPC-GENE cohort, respectively. Next, adjacent genes exhibiting the same CNA profiles were grouped into regions to further reduce the number of tests. Boschloo's exact test (one-sided, R-package 'Exact') was applied to regions with CNAs in at least $10 \%$ of all samples to identify events that occurred significantly more often in samples with CR/IDC. Multiple testing correction was performed via false discovery rate (FDR) and regions with a q-value below 0.05 were considered significant. To integrate both cohorts, all genes in regions that were identified as significant in the TCGA cohort were tested in the CPC-GENE 
cohort. Genes with a q-value below 0.1 were considered validated. A logistic regression was used to assess which individual deletion or amplification events were predictive for CR/IDC status while accounting for PGA and GS as confounding factors. To account for correlations between PGA and individual CNAs, PGA was re-calculated for each event by excluding the chromosome the particular event was located on. Visualization of results was done with BoutrosLab.plotting.general R-package (v5.6.10; P'ng et al. in review).

\section{ERG expression, chromothripsis and kataegis}

To quantify ERG expression in the TCGA cohort, RSEM 'scaled estimates' were obtained via TCGA-Assembler and multiplied by $10^{6}$ to convert them to transcripts per million (TPM). Subsequently a $\log _{10}$ transformation was applied and UCSC transcript uc002yxa.2 was used to estimate ERG expression. Deletion events located between TMPRSS2 and ERG were determined by combining deletions of the genes ETS2, BACE2, BRWD1, PSMG1 and HMGN1. For the CPC-GENE cohort, scores for chromothripsis and kataegic regions were computed using the ShatterProof [31] and SeqKat (Fraser et al. Nature, in press) algorithms. The maximum values for each sample were used for comparison (Wilcoxon-Mann-Whitney test) to ascertain that despite their rare occurrence, any presence of these phenomena in the CPC-GENE samples could be detected and tested for association with CR/IDC.

\section{Somatic mutations}

Automated and curated somatic mutation calls for exome sequencing data from TCGA PRAD samples were obtained via the TCGA Data Portal (https://tcgadata.nci.nih.gov/). Functional events were summarized patient-wise for each gene (i.e. multiple mutations in one gene were only counted once per patient, excluding categories 'Silent' and 'RNA'). In addition, non-recurrent events and events that occurred in less than $5 \%$ of all tested samples were excluded from further analysis; all remaining gene mutations were tested for significant enrichment in CR/IDC positive samples using Boschloo's exact test (one-sided, R-package 'Exact'). CPC-GENE whole genome sequencing-derived SNVs (Fraser et al. Nature, in press) were filtered to only include functional mutations located in exonic regions and then processed as described above.

\section{Results}

\section{Patient characteristics}

Patient characteristics of both TCGA $(n=260)$ and CPC-GENE $(n=199)$ cohorts are listed in Table 1 . The TCGA cohort included more patients with adverse characteristics than the CPC-GENE cohort, having higher
PSA levels (Wilcoxon rank sum test, $p=2.2 \cdot 10^{-16}$ ), GS (Pearson's $\mathrm{X}^{2}$ test, $p=4.0 \cdot 10^{-5}$ ) and $\mathrm{pT}$ stage (Pearson's $\mathrm{X}^{2}$ test, $p=3.1 \cdot 10^{-9}$ ), which can be explained by the specific inclusion of clinically intermediate-risk disease in the latter cohort. Moreover, tumour cellularity was higher in TCGA than CPC-GENE (Additional file 1: Figure S1). Representative prostate cancer samples of GS 6 and $G S \geq 7$ are depicted in Fig. 1 .

\section{CR/IDC is associated with genomic instability}

To assess whether CR/IDC was associated with genomic instability, we calculated PGA for all patients and used a Wilcoxon-test to identify significant differences [17, 26]. PGA was 3 fold $\left(p=1.6 \cdot 10^{-4}\right)$ higher in men with CR/ IDC as compared to men without (Fig. 2). Exclusion of men with GS 6, who generally lack CR/IDC growth, yielded similar results with 2.2 fold $\left(\mathrm{p}=3 \cdot 10^{-4}\right)$ PGA increase in cases containing CR/IDC. Subgroup analysis revealed that PGA was significantly higher in samples with CR/IDC in GS $4+3=7$ (2.2 fold; $p=5.3 \cdot 10^{-3}$ ), but not in GS $3+4=7$ (2.1 fold; $p=0.19$ ), GS 8 (5.1 fold; $p=0.57$ ) and GS 9-10 (1.7 fold; $p=0.10)$. Moreover, PGA scores did not differ significantly between GS $3+4=$ 7 without CR/IDC pattern and GS 6 (1.2 fold; $p=0.51)$. Validation within the CPC-GENE cohort revealed overall 1.7 fold higher PGA of CR/IDC positive men with GS $\geq 3+4=7 \quad\left(p=4 \cdot 10^{-3}\right)$. Subgroup analysis showed 1.3 fold $(p=0.02)$ higher PGA in GS $3+4=7$ cases with CR/IDC as compared to those without. PGA scores were significantly lower in GS 6 as compared to GS $3+4=7$ with CR/IDC ( 2.2 fold; $p=4.7 \cdot 10^{-7}$ ) than those without CR/IDC (1.6 fold; $p=0.07$ ). Since 32 out of 35 CPCGENE patients with $\mathrm{GS} \geq 4+3=7$ had $\mathrm{CR} / \mathrm{IDC}$, statistical analysis in respective subgroups lacked statistical power.

To determine whether genomic instability in CR/IDC was a global phenomenon or affected specific genomic regions, we computed PGA for individual chromosome arms utilizing deletion and amplification events independently. We found that deletions were mostly present on chromosome arms 1p, 4p, 4q, 5q, 7q, 8p, $10 \mathrm{p}, 10 \mathrm{q}, 12 \mathrm{p}, 13 \mathrm{q}, 16 \mathrm{q}, 17 \mathrm{p}, 18 \mathrm{q}$ and $21 \mathrm{q}$ in samples with CR/IDC $(p<0.05$, Additional file 1: Figs. S2 and S3; Additional file 2: Table S1), while amplifications were found on chromosome 4q, 8p, 8q, 9p, 14q and 18p. Several of these chromosome arms have been linked to advanced prostate cancer [21, 32-35]. Increased PGA for chromosome $4 \mathrm{p}, 8 \mathrm{p}, 10 \mathrm{q}, 12 \mathrm{p}$ and $16 \mathrm{q}$ deletions were also present in the CPC-GENE cohort $(p<0.05$, Additional file 1: Figs. S4 and S5; Additional file 2: Table S1).

Somatic CNAs associated with aggressive clinical outcome are enriched in $\mathrm{CR} / \mathrm{IDC}$

To identify somatic CNAs associated with CR/IDC, we applied Boschloo's exact test, independently for each 
Table 1 Clinical and pathological patient characteristics of the TCGA and CPC-GENE cohorts

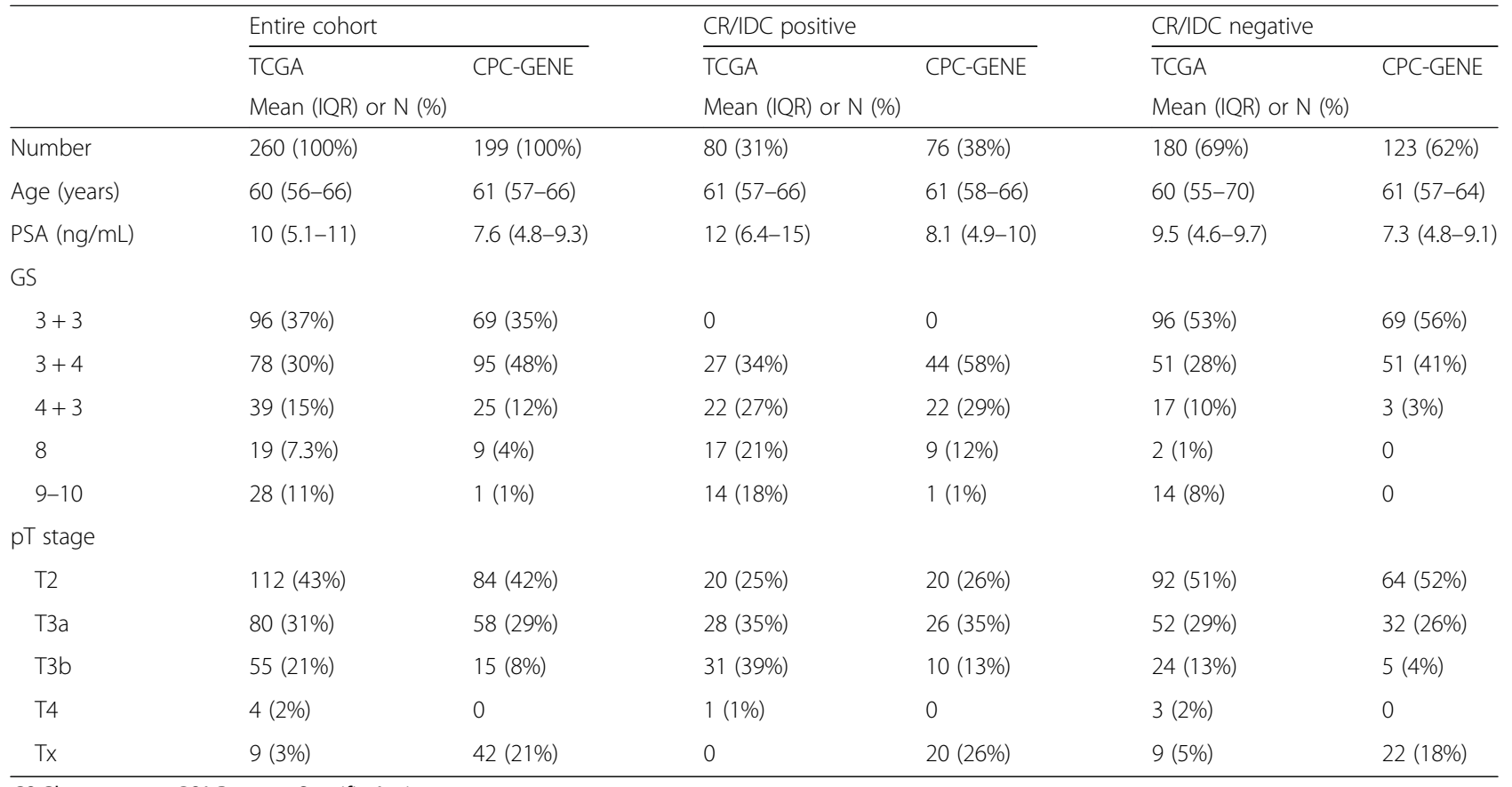

GS Gleason score, PSA Prostate Specific Antigen

gene locus in $\mathrm{GS} \geq 3+4=7$ samples. We found 592 gene deletions and 366 amplifications significantly associated with CR/IDC $(q<0.05)$. These events clustered in specific chromosomal regions known to be associated with aggressive disease such as deletions of $8 \mathrm{p}$ (PPP2R2A, NKX3-1) [36-38], 16q22 (CDH1) [39], 16q23 (BCAR1, CTRB1, CTRB2, WWOX and MAF) [15, 40, 41], 16q24 [42], 10q23 (PTEN) [43, 44], 17p13 and 18q21 (CCBE1) [45] as well as amplification of 8q24 (MYC and LY6 family members [15, 46, 47], Fig. 3 and Additional file 3: Table S2).
Since it was unclear whether genomic alterations occurred specifically in CR/IDC structures or also in noncribriform prostate cancer glands adjacent to CR/IDC, we excluded samples with $<30 \% \mathrm{CR} / \mathrm{IDC}$ growth pattern. Comparing GS $\geq 3+4=7$ men with $\geq 30 \%$ CR/IDC $(n=44)$ to those without $(n=84)$ resulted in a total of 1299 significant deletions and 369 amplifications. Additional deletions in cases with $\geq 30 \%$ CR/IDC included the "Down syndrome critical region" located between ERG and TMPRSS2 on 21q22 [48], 16q22

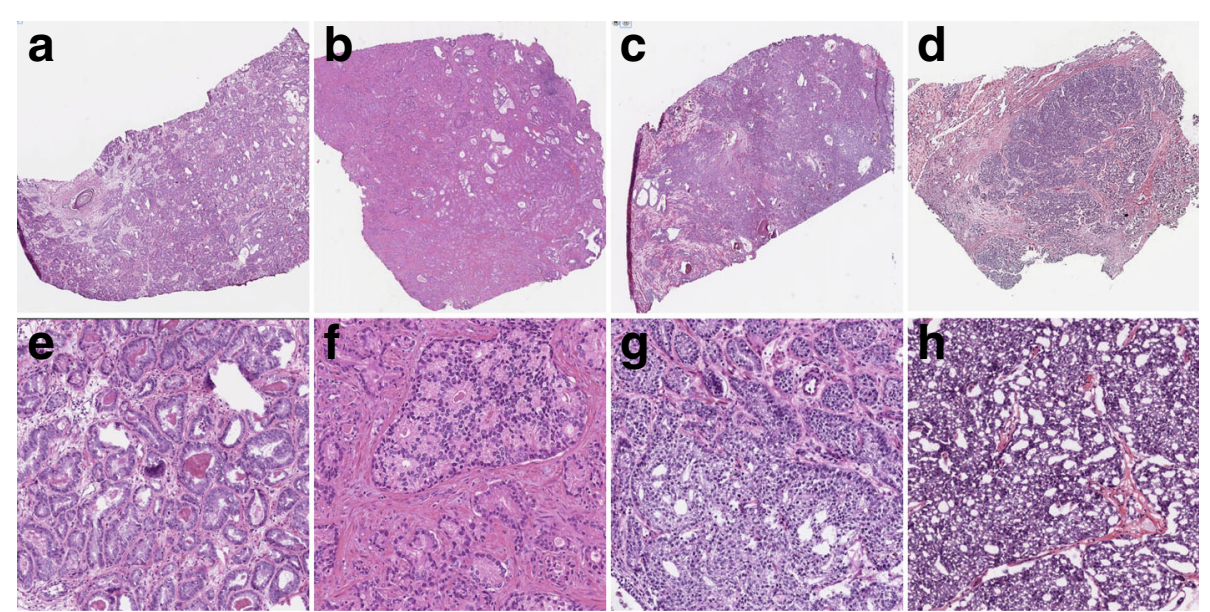

Fig. 1 Representative images of reference HE slides of GS $6(\mathbf{a}, \mathbf{e})$ without CR/IDC, and GS $3+4=7(\mathbf{b}, \mathbf{f}), 4+3=7(\mathbf{c}, \mathbf{g})$ and $4+4=8(\mathbf{d}, \mathbf{h})$ with CR/IDC growth 

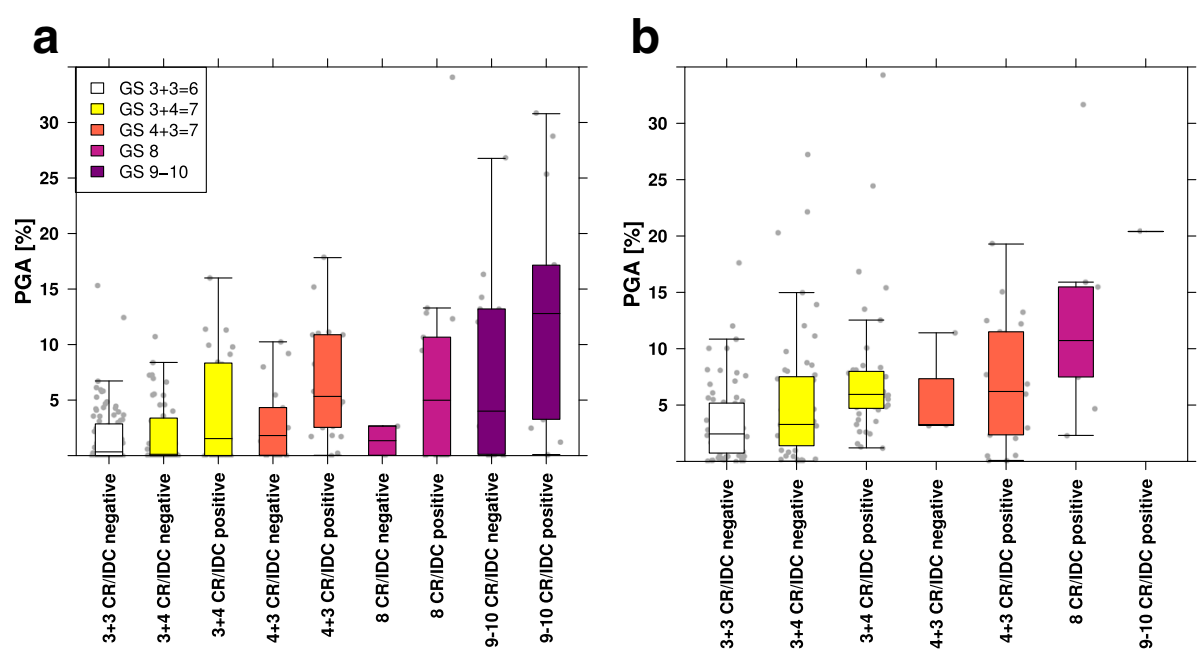

Fig. 2 Boxplot of patient-wise PGA stratified by CR/IDC percentage and Gleason score in the TCGA (a) and CPC-GENE (b) cohort

(CTCF) [49], 13q14 (RB1) [50, 51], 17p13 (TP53) [52], and parts of 6q [53, 54] (Additional file 4: Table S3). Although genetic deletions of genes located between the TMPRSS2 promoter and ERG occurred more frequently in CR/IDC cases, we were unable to find a significant difference in ERG mRNA expression (Additional file 1: Figure S6). This paradoxical finding might be explained by relatively more frequent genomic translocation than deletion mechanism for TMPRSS2:ERG corresponding to lower genomic instability in cases without CR/IDC [55].

A trend towards lower q-values was observed when excluding tumours with $<30 \% \mathrm{CR} / \mathrm{IDC}$ pattern suggesting that signal strength from CR/IDC specific events was diluted in cases with low CR/IDC quantity. Subsequent analyses were all performed using CR/IDC samples with at least 30\% cribriform architecture. In total 474 deleted and 328 amplified genes were validated in the CPC-GENE cohort ( $\mathrm{q}<0.1$ ), located on chromosomes $8 \mathrm{p}, 10 \mathrm{q} 23,13 \mathrm{q} 22$, 16q23-24, 17p13, 21q22, as well as $8 \mathrm{q} 24$, respectively (Additional file 5: Table S4 and Additional file 6: Figure S7). We noticed that q-values were generally lower in TCGA as compared to CPC-GENE, regardless of whether a threshold on CR/IDC was applied or not, indicating relatively lower statistical power of the latter cohort.

Since genomic instability and GS might act as confounding factors in assessing CNA events, we performed logistic regression analysis correcting for GS and PGA based on the 1668 previously identified events. A total of 779 gene deletions and 317 amplifications were independently associated with CR/IDC $(\mathrm{q}<0.1$, Additional file 7: Table S5). Deletions were mostly located on 8p21-23, 13q14, 16q2124 as well as $18 \mathrm{q} 21-23$, but also included the genomic loci containing PTEN (10q23) [56], RYBP/FOXP1 (3p13) [16] and CASP8AP2 (6q15) [57]. The PPP2R2A/BNIP3L/ $P N M A 2$ locus (8p21) [36] featured the lowest q-value for deletions $(p=0.00018, \mathrm{q}=0.02$, $\mathrm{OR}=10.2,3.24-38)$, while the MAFA/PTP4A3 locus on 8q24 did for amplifications $(p=0.007, \mathrm{q}=0.08, \mathrm{OR}=7.77,1.98-41.95) \quad[58,59]$. For CPC-GENE, logistic regression did not yield significant results after correcting for multiple comparisons, which can be attributed to lower statistical power and significant differences in pathological features.

\section{Somatic SNVs are not main driver events for CR/IDC growth}

To identify genes affected by functional SNVs we used TCGA exome sequencing data (https://tcga-data.nci. nih.gov/) of samples with $\mathrm{GS} \geq 7$, and compared 88 samples with $\geq 30 \%$ CR/IDC against 143 without. Filtering for genes that harboured SNVs in at least 5\% of all samples, FOXA1 (15\% versus 5\%; $\mathrm{p}=0.007)$, TP53 and SPOP (both $19 \%$ versus $10 \% ; p=0.035$ ) showed significantly higher mutation rates in cases with CR/IDC compared to those without (Boschloo's exact test). Although SNV data were available for CPC-GENE samples, the number of cases, i.e. 8 with and 30 without CR/IDC was too low for statistical analysis. We did not find significant differences in overall frequency or total number of affected genes with functional SNVs (data not shown), indicating that SNVs are unlikely to be driver events for CR/IDC growth.

Finally, we investigated whether recently discovered DNA repair-related phenomena were linked to CR/IDC $[60,61]$. We utilized available computational scores for kataegis, a pattern of localized hypermutation, and chromothripsis, a catastrophic event during which single chromosome arms or entire chromosomes are rearranged and/or lost. No statistically significant differences could be identified between cases with and without CR/IDC albeit sample numbers were low (data not shown). 


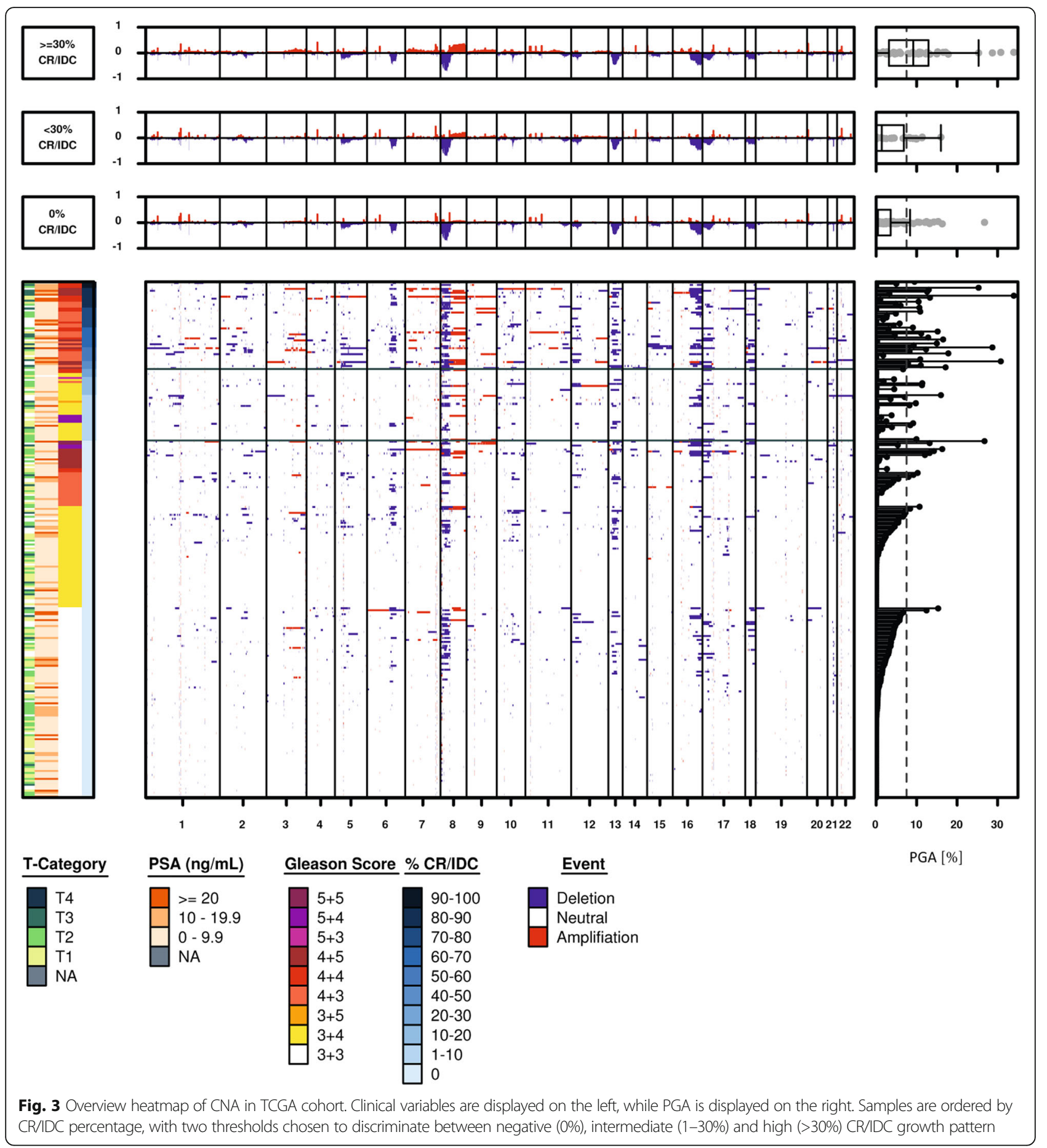

\section{Discussion}

Recent studies have indicated the clinical importance of both invasive cribriform and intraductal carcinoma of the prostate $[6,13,14]$. In the current study, we hypothesized that CR/IDC represents a morphologic substrate of genomic alterations associated with aggressive disease. We found that CR/IDC was associated with increased genomic instability together with chromosomal deletions of 3p13, 6q15, 8p21-23, 10q23, 13q14, 16q21-24, $18 \mathrm{q} 21-23$, and amplification of $8 \mathrm{q} 24$. The genetic losses and amplifications included several genes related to aggressive prostate cancer such as loss of PTEN, RB1, TP53 and amplification of $M Y C$. Altogether, these findings support our hypothesis that CR/IDC is a specific morphologic substrate of genomic alterations associated with aggressive disease. 
Our study is in line with previous studies on genetic abnormalities related to CR/IDC growth. Dawkins et al. [62] and Bettendorf et al. [63] observed more frequently loss of heterozygosity $(\mathrm{LOH})$ in IDC than in the invasive prostate cancer component. Qian et al. showed gain of chromosomes 7, 12, and $\mathrm{Y}$, loss of chromosome 8 , and amplification of $c-M Y C$ in cribriform cancer compared to other Gleason grade 3 and 4 patterns [64]. In a meta-analysis on recurrent CNAs, Williams et al. [33] compared 568 primary prostate cancer tumour samples from 8 previous studies [16, 19, 20, 65-69] with 115 metastatic prostate cancer samples from 5 studies $[16,22,67,70,71]$. Strikingly, the prevalence of recurrent CNAs in metastatic prostate cancers corresponded with several of the CNAs found enriched in CR/IDC, such as PTEN and NKX3-1. Recently, Chua et al. studied differences in RNA expression in prostate cancer with and without CR/IDC. They found that the long non-coding RNA SChLAP1, which has been associated with tumour progression, was significantly higher in CR/IDC, and that CR/IDC growth was associated with hypoxia [72-74]. Together these findings further support a strong relation of CR/IDC with molecular tumour progression. On the other hand, we did not find a statistically significant difference between GS $3+4=7$ without CR/IDC and GS 6 cases, which further supports the question whether it is clinically relevant to distinguish CR/IDC-negative GS $3+4=7$ from GS 6 prostate cancer cases.

Although prostate cancer with CR/IDC showed increased genomic instability, it is not yet clear to what extent these molecular alterations are exclusively present in $\mathrm{CR} / \mathrm{IDC}$ tumour glands or whether these alterations can also be found in surrounding non-cribriform tumour glands. Using RNA in situ hybridization, we previously found that SChLAP1 was not only over-expressed in CR/ IDC structures but also in adjacent non-cribriform cancer glands suggesting that it represents a field effect during tumour progression and not a specific characteristic of CR/IDC growth [72, 75]. In our study, CR/IDC was more frequently present in cases with higher GS. To exclude that genomic alterations were merely relating to higher GS and not to CR/IDC per se, we performed PGA subgroup analysis and logistic regression for CNAs, which indeed revealed an independent associated with CR/IDC in the TCGA cohort. Further comparisons of microdissected growth patterns within individual patients are mandatory to determine what events are specific for CR/IDC and which represent general effects of progression.

Elucidation of the molecular alterations associated to CR/IDC is not only of interest for molecular-biology, but might also have future impact for prostate cancer diagnosis and management. Prostate biopsies only sample a limited volume of the entire tumour and might be falsenegative for CR/IDC due to sampling artefact. Since IDC represents an extensive proliferation of neoplastic cells within pre-existent acini which connect with the urethra, we postulate that these cells and/or their DNA can be shed into urine. Identification of molecular alterations associated with CR/IDC in voided urine could form the base of non-invasive tests for detection of aggressive CR/IDC.

The current study has several limitations. While we set out to validate our findings in an independent cohort, we noticed that many events originally found in the TCGA cohort could not be confirmed in the CPC-GENE dataset. This may be explained by differences in cohort composition, since the TCGA was enriched for tumours with adverse pathologic features. In addition, the statistical power of the CPC-GENE cohort was lower than of the TCGA, as its study population was smaller, included samples with lower and more variable tumour percentage, and was strongly enriched for CR/IDC in GS 8-10. Nevertheless, both datasets independently revealed the association of $\mathrm{CR} / \mathrm{IDC}$ with increased genomic instability and the deletions of various specific genomic regions and genes. Furthermore, tumour heterogeneity and sampling artefacts may have also influenced the outcome of this study, as our current data was based on DNA derived from a freshly frozen section per patient. Hence, there may have been, for instance, CR/IDC growth in an adjacent region that was not sampled for genomic analysis that may have been detected due to a field effect. This might be the cause of the relatively small effect sizes in the current study. Lastly, we did not independently analyse CR/IDC growth in relation to adjacent tumour glands using, for instance, laser-capture microdissection or in situ hybridization.

\section{Conclusion}

We found that pathologic CR/IDC growth pattern is associated genomic instability including deletions of $8 \mathrm{p}$, $10 \mathrm{q} 23,13 \mathrm{q} 22,16 \mathrm{q} 22-24,17 \mathrm{p} 13$ and $21 \mathrm{q} 22$, as well as smaller 8q24 amplification. These results indicate that CR/IDC is a histopathological substrate of molecular tumour progression and present a rationale for its aggressive clinical behaviour.

\section{Additional files}

Additional file 1: Figure S1. Comparison of tumour cell percentage in whole-slide reference images for both TCGA and CPC-GENE cohorts, stratified by CR/IDC status. Figure S2. PGA for deletion events in the TCGA cohort per chromosome arm for GS $\geq 3+4=7$ with and without CR/IDC. Figure S3. PGA for amplification events in the TCGA cohort per chromosome arm for $\mathrm{GS} \geq 3+4=7$ with and without CR/IDC. Figure S4. PGA for deletion events in the CPC-GENE cohort per chromosome arm for GS $\geq 3+4=7$ with and without CR/IDC. Figure S5. PGA for amplification events in the CPC-GENE cohort per chromosome arm for GS $\geq 3+4=7$ with and without CR/IDC. Figure S6. Overview of ERG expression in TCGA $\left[\log _{10}(\mathrm{TPM})\right]$ stratified by CR/ IDC status (A) and deletion of the genomic region between TMPRSS2 and ERG (B). (PDF $3140 \mathrm{~kb}$ ) 
Additional file 2: Table S1. Overview of genomic instability of individual chromosome arms in both TCGA and CPC-GENE datasets. Genomic instability was calculated based on a modified PGA formula (see methods). $P$-values are based on a Wilcon-Mann-Whitney test while log2FC represents the $\log _{2}$ ratio of the average PGA scores for CR/IDC positive samples and CR/IDC negative samples. PGA scores for deletions and amplifications were calculated and tested separately. (XLS $139 \mathrm{~kb}$ )

Additional file 3: Table S2. Gene-wise copy number alterations associated with CR/IDC growth using any CR/IDC presence for patient stratification. Columns contain: Symbol - official gene symbol, Chromosome / Start / End - genomic coordinates of gene locus, FDR - Boschloo's exact test $p$-value after correcting for multiple tests using the Benjamini-Hochberg procedure. amplifications_case - number of CR/IDC positive samples with an amplification spanning gene locus, amplifications_control - number of control samples with an amplification spanning gene locus, cases - total number of CR/IDC positive samples, controls - total number of control samples. All entries are sorted by genomic location. Deletions are presented in the same format and listed separately. (XLS $226 \mathrm{~kb}$ )

Additional file 4: Table S3. Gene-wise copy number alterations associated with CR/IDC growth using a $\geq 30 \%$ CR/IDC threshold to stratify samples. Columns contain: Symbol - official gene symbol, Chromosome / Start / End - genomic coordinates of gene locus, FDR - Boschloo's exact test $p$ value after correcting for multiple tests using the Benjamini-Hochberg procedure. amplifications_case - number of CR/IDC positive samples with an amplification spanning gene locus, amplifications_control - number of control samples with an amplification spanning gene locus, cases - total number of CR/IDC positive samples, controls - total number of control samples. All entries are sorted by genomic location. Deletions are presented in the same format and listed separately. (XLS $161 \mathrm{~kb}$ )

Additional file 5: Table S4. Gene-wise copy number alterations detected in the TCGA cohort and validated in the CPC-GENE cohort using $a \geq 30 \%$ CR/IDC threshold to stratify samples. Columns contain: Symbol official gene symbol, Chromosome / Start / End - genomic coordinates of gene locus, FDR - Boschloo's exact test p-value after correcting for multiple tests using the Benjamini-Hochberg procedure for specified dataset. amplifications_case - number of CR/IDC positive samples in specified dataset with an amplification spanning gene locus, amplifications_control - number of control samples in specified dataset with an amplification spanning gene locus, cases - total number of CR/IDC positive samples in specified dataset, controls - total number of control samples in specified dataset. All entries are sorted by genomic location. Deletions are presented in the same format and listed separately. (PDF $12328 \mathrm{~kb}$ )

Additional file 6: Figure S7. Overview heatmap of copy number alterations in CPC-GENE cohort. Clinical variables are displayed on the left, while percent genome altered (PGA) is displayed on the right. Samples are ordered by CR/DC percentage, with two thresholds chosen to discriminate between negative (0\%) and intermediate (<30\%) CR/IDC status. (XLSX $14 \mathrm{~kb}$ )

Additional file 7: Table S5. Significant CNAs identified by logistic regression analysis accounting for genomic instability as confounding factor in the TCGA dataset. Columns contain: Symbol - official gene symbol, Chromosome / Start / End - genomic coordinates of gene locus, $p$-alue / FDR - p-value of logistic regression before and after correction for multiple tests via FDR, odds ratio / 95\% Cl - odds ratio and 95\% confidence interval based on logistic regression. Deletions and amplifications are presented in the same format and listed separately. All entries are sorted by genomic location. (XLS 266 kb)

\section{Acknowledgements}

The results shown here are in whole or part based upon data generated by the TCGA Research Network: http://cancergenome.nih.gov/.

\section{Funding}

Research was conducted with the support of the Ontario Institute for Cancer Research and through funding provided by the Government of Ontario as well as the Center for Translational Molecular Medicine (CTMM, The Netherlands, NGS ProToCol project grant 03O-402). This work was also supported by Prostate Cancer Canada and is by the Movember Foundation (Grant \#RS2014-01). Dr. Boutros was supported by a Terry Fox Research Institute New Investigator Award and a CIHR
New Investigator Award. The funders had no role in study design, data collection and analysis, decision to publish, or preparation of the manuscript.

\section{Availability of data and materials}

All TCGA related data can be obtained from the TCGA Data Portal via https:/tcga-data.nci.nih.gov/.

\section{Authors' contributions}

Pathology analyses: C.F.K., G.J.L.H.V.L. and T.v.d.K. Statistical and bioinformatics analyses: R.B., J.L., T.N.Y., E.L., V.H., F.Y. Clinical Assessment of samples from the CPC-GENE cohort: M.F., R.G.B. and T.v.d.K. Wrote the first draft of the manuscript: R.B., C.F.K and G.J.L.H.v.L. Initiated the project: R.B., C.F.K., G.J. G.J.L.H.v.L, T.v.d.K., and P.C.B. Supervised research: T.v.d.K, G.J., P.C.B and G.J.L.H.V.L. Approved the manuscript: all authors.

\section{Ethics approval and consent to participate}

Not applicable.

\section{Consent for publication}

Not applicable.

\section{Competing interests}

The authors declare that they have no competing interests.

\section{Publisher's Note}

Springer Nature remains neutral with regard to jurisdictional claims in published maps and institutional affiliations.

\section{Author details}

${ }^{1}$ Department of Urology, Erasmus MC, Rotterdam, the Netherlands. ${ }^{2}$ Department of Pathology, Erasmus University Medical Center, Josephine Nefkens Institute building, Be-222, P.O. Box 2040, Rotterdam 3000 CA, The Netherlands. ${ }^{3}$ Informatics \& Biocomputing Program, Ontario Institute for Cancer Research, Toronto, ON, Canada. ${ }^{4}$ Department of Medical Biophysics, University of Toronto, Toronto, ON, Canada. ${ }^{5}$ Ontario Cancer Institute, Princess Margaret Cancer Centre, University Health Network, Toronto, ON, Canada. ${ }^{6}$ Department of Radiation Oncology, University of Toronto, Toronto, ON, Canada. ${ }^{7}$ Department of Pathology and Laboratory Medicine, Toronto General Hospital, University Health Network, Toronto, ON, Canada. ${ }^{8}$ Department of Pharmacology and Toxicology, University of Toronto, Toronto, ON, Canada.

Received: 17 May 2017 Accepted: 21 December 2017 Published online: 02 January 2018

\section{References}

1. Epstein JI, Egevad L, Amin MB, Delahunt B, Srigley JR, Humphrey PA. The 2014 International Society of Urological Pathology (ISUP) consensus conference on Gleason grading of prostatic carcinoma: definition of grading patterns and proposal for a new grading system. Am J Surg Pathol. 2016;40:244-52.

2. Kweldam CF, Wildhagen MF, Bangma CH, van Leenders GJLH. Diseasespecific death and metastasis do not occur in patients with Gleason score $\leq 6$ at radical prostatectomy. BJU Int. 2015;116:230-5.

3. Iczkowski KA, Torkko KC, Kotnis GR, Wilson RS, Huang W, Wheeler TM, Abeyta AM, La Rosa FG, Cook S, Werahera PN, Lucia MS. Digital quantification of five high-grade prostate cancer patterns, including the cribriform pattern, and their association with adverse outcome. Am J Clin Pathol. 2011;136:98-107.

4. Kryvenko ON, Gupta NS, Virani N, Schultz D, Gomez J, Amin A, Lane Z, Epstein JI. Gleason score 7 adenocarcinoma of the prostate with lymph node metastases: analysis of 184 radical prostatectomy specimens. Arch Pathol Lab Med. 2013;137:610-7.

5. Dong F, Yang P, Wang C, Wu S, Xiao Y, McDougal WS, Young RH, Wu C-L, Architectural heterogeneity and cribriform pattern predict adverse clinical outcome for Gleason grade 4 prostatic adenocarcinoma. Am J Surg Pathol. 2013;37:1855-61.

6. Kweldam CF, Wildhagen MF, Steyerberg EW, Bangma $\mathrm{CH}$, van der Kwast $\mathrm{TH}$, van Leenders GJLH. Cribriform growth is highly predictive for postoperative metastasis and disease-specific death in Gleason score 7 prostate cancer. Mod Pathol. 2015;28:457-64. 
7. Van der Kwast T, Al Daoud N, Collette L, Sykes J, Thoms J, Milosevic M, Bristow RG, Van Tienhoven G, Warde P, Mirimanoff R-O, Bolla M. Biopsy diagnosis of intraductal carcinoma is prognostic in intermediate and high risk prostate cancer patients treated by radiotherapy. Eur J Cancer. 2012;48: 1318-25.

8. Kimura K, Tsuzuki T, Kato M, Saito AM, Sassa N, Ishida R, Hirabayashi H, Yoshino Y, Hattori R, Gotoh M. Prognostic value of intraductal carcinoma of the prostate in radical prostatectomy specimens. Prostate. 2014;74:680-7.

9. Guo CC, Epstein J. Intraductal carcinoma of the prostate on needle biopsy: Histologic features and clinical significance. Mod Pathol. 2006;19: 1528-35.

10. Robinson BD, Epstein Jl. Intraductal carcinoma of the prostate without invasive carcinoma on needle biopsy: emphasis on radical prostatectomy findings. J Urol. 2010;184:1328-33.

11. Watts K, Li J, Magi-Galluzzi C, Zhou M. Incidence and clinicopathological characteristics of intraductal carcinoma detected in prostate biopsies: a prospective cohort study. Histopathology. 2013;63:574-9.

12. Chen Z, Chen N, Shen P, Gong J, Li X, Zhao T, Liao B, Liu L, Liu Z, Zhang X, Liu J, Peng Z, Chen X, Xu M, Gui H, Zhang P, Wei Q, Zhou Q, Zeng H. The presence and clinical implication of intraductal carcinoma of prostate in metastatic castration resistant prostate cancer. Prostate. 2015;75:1247-54.

13. Kweldam CF, Kümmerlin IP, Nieboer D, Verhoef El, Steyerberg EW, van der Kwast TH, Roobol MJ, van Leenders GJ. Disease-specific survival of patients with invasive cribriform and intraductal prostate cancer at diagnostic biopsy. Mod Pathol. 2016;29:630-6.

14. Trudel D, Downes MR, Sykes J, Kron KJ, Trachtenberg J, van der Kwast TH. Prognostic impact of intraductal carcinoma and large cribriform carcinoma architecture after prostatectomy in a contemporary cohort. Eur J Cancer. 2014:50:1610-6.

15. Lapointe J, Li C, Giacomini CP, Salari K, Huang S, Wang P, Ferrari M, Hernandez-Boussard T, Brooks JD, Pollack JR. Genomic profiling reveals alternative genetic pathways of prostate tumorigenesis. Cancer Res. 2007;67:8504-10.

16. Taylor BS, Schultz N, Hieronymus H, Gopalan A, Xiao Y, Carver BS, Arora VK, Kaushik P, Cerami E, Reva B, Antipin Y, Mitsiades N, Landers T, Dolgalev I, Major JE, Wilson M, Socci ND, Lash AE, Heguy A, Eastham JA, Scher HI Reuter VE, Scardino PT, Sander C, Sawyers CL, Gerald WL. Integrative genomic profiling of human prostate cancer. Cancer Cell. 2010;18:11-22.

17. Lalonde E, Ishkanian AS, Sykes J, Fraser M, Ross-Adams H, Erho N, Dunning MJ, Halim S, Lamb AD, Moon NC, Zafarana G, Warren AY, Meng X, Thoms J, Grzadkowski MR, Berlin A, Have CL, Ramnarine VR, Yao CQ, Malloff CA, Lam LL, Xie H, Harding NJ, Mak DYF, Chu KC, Chong LC, Sendorek DH, P'ng C, Collins CC, Squire JA, et al. Tumour genomic and microenvironmental heterogeneity for integrated prediction of 5-year biochemical recurrence of prostate cancer: a retrospective cohort study. Lancet Oncol. 2014;15:1521-32.

18. Baca SC, Prandi D, Lawrence MS, Mosquera JM, Romanel A, Drier Y, Park K, Kitabayashi N, MacDonald TY, Ghandi M, Van Allen E, Kryukov GV, Sboner A, Theurillat J-P, Soong TD, Nickerson E, Auclair D, Tewari A, Beltran H, Onofrio RC, Boysen G, Guiducci C, Barbieri CE, Cibulskis K, Sivachenko A, Carter SL, Saksena G, Voet D, Ramos AH, Winckler W, et al. Punctuated evolution of prostate cancer genomes. Cell. 2013;153:666-77.

19. Boyd LK, Mao X, Xue L, Lin D, Chaplin T, Kudahetti SC, Stankiewicz E, Yu Y, Beltran L, Shaw G, Hines J, Oliver RTD, Berney DM, Young BD, Y-J L. Highresolution genome-wide copy-number analysis suggests a monoclonal origin of multifocal prostate cancer. Genes Chromosomes Cancer. 2012;51: 579-89.

20. Beroukhim R, Mermel CH, Porter D, Wei G, Raychaudhuri S, Donovan J, Barretina J, Boehm JS, Dobson J, Urashima M, Mc Henry KT, Pinchback RM, Ligon AH, Cho Y-J, Haery L, Greulich H, Reich M, Winckler W, Lawrence MS, Weir BA, Tanaka KE, Chiang DY, Bass AJ, Loo A, Hoffman C, Prensner J, Liefeld T, Gao Q, Yecies D, Signoretti S, et al. The landscape of somatic copy-number alteration across human cancers. Nature. 2010;463:899-905.

21. Sun J, Liu W, Adams TS, Sun J, Li X, Turner AR, Chang B, Kim JW, Zheng SL, Isaacs WB, Xu J. DNA copy number alterations in prostate cancers: a combined analysis of published CGH studies. Prostate. 2007:67:692-700

22. Liu W, Laitinen S, Khan S, Vihinen M, Kowalski J, Yu G, Chen L, Ewing CM, Eisenberger MA, Carducci MA, Nelson WG, Yegnasubramanian S, Luo J, Wang Y, Xu J, Isaacs WB, Visakorpi T, Bova GS. Copy number analysis indicates monoclonal origin of lethal metastatic prostate cancer. Nat Med. 2009;15:559-65
23. Forbes SA, Tang G, Bindal N, Bamford S, Dawson E, Cole C, Kok CY, Jia M, Ewing R, Menzies A, Teague JW, Stratton MR, Futreal PA. COSMIC (the catalogue of somatic mutations in cancer): a resource to investigate acquired mutations in human cancer. Nucleic Acids Res. 2010; 38(Database issue):D652-7.

24. Forbes $S A$, Beare $D$, Gunasekaran $P$, Leung $K$, Bindal N, Boutselakis $H$, Ding M, Bamford S, Cole C, Ward S, Kok CY, Jia M, De T, Teague JW, Stratton MR, McDermott U, Campbell PJ. COSMIC: exploring the world's knowledge of somatic mutations in human cancer. Nucleic Acids Res. 2014;43(Database issue):D805-11.

25. Robinson D, Van Allen EM, Y-M W, Schultz N, Lonigro RJ, Mosquera J-M, Montgomery B, Taplin M-E, Pritchard CC, Attard G, Beltran H, Abida W, Bradley RK, Vinson J, Cao X, Vats P, Kunju LP, Hussain M, Feng FY, Tomlins SA, Cooney KA, Smith DC, Brennan C, Siddiqui J, Mehra R, Chen Y, Rathkopf DE, Morris MJ, Solomon SB, Durack JC, et al. Integrative clinical genomics of advanced prostate cancer. Cell. 2015;161:1215-28.

26. Hieronymus H, Schultz N, Gopalan A, Carver BS, Chang MT, Xiao Y, Heguy A, Huberman K, Bernstein M, Assel M, Murali R, Vickers A, Scardino PT, Sander C, Reuter V, Taylor BS, Sawyers CL. Copy number alteration burden predicts prostate cancer relapse. Proc Natl Acad Sci U S A. 2014;111:11139-44.

27. Boutros PC, Fraser M, Harding NJ, de Borja R, Trudel D, Lalonde E, Meng A, Hennings-Yeomans PH, McPherson A, Sabelnykova VY, Zia A, Fox NS, Livingstone J, Shiah Y-J, Wang J, Beck TA, Have CL, Chong T, Sam M, Johns J, Timms L, Buchner N, Wong A, Watson JD, Simmons TT, P’ng C, Zafarana G, Nguyen F, Luo X, Chu KC, et al. Spatial genomic heterogeneity within localized, multifocal prostate cancer. Nat Genet. 2015;47:736-45

28. Cooper CS, Eeles R, Wedge DC, Van Loo P, Gundem G, Alexandrov LB, Kremeyer B, Butler A, Lynch AG, Camacho N, Massie CE, Kay J, Luxton HJ, Edwards S, Kote-Jarai Z, Dennis N, Merson S, Leongamornlert D, Zamora J, Corbishley C, Thomas S, Nik-Zainal S, Ramakrishna M, O'Meara S, Matthews L, Clark J, Hurst R, Mithen R, Bristow RG, Boutros PC, et al. Analysis of the genetic phylogeny of multifocal prostate cancer identifies multiple independent clonal expansions in neoplastic and morphologically normal prostate tissue. Nat Genet. 2015;47:367-72.

29. Lindberg J, Kristiansen A, Wiklund P, Grönberg H, Egevad L. Tracking the origin of metastatic prostate cancer. Eur Urol. 2015;67:819-22.

30. Zhu Y, Qiu P, Ji Y. TCGA-assembler: open-source software for retrieving and processing TCGA data. Nat Methods. 2014;11:599-600.

31. Govind SK, Zia A, Hennings-Yeomans PH, Watson JD, Fraser M, Anghel C, Wyatt AW, van der Kwast T, Collins CC, MCPherson JD, Bristow RG, Boutros PC. ShatterProof: operational detection and quantification of chromothripsis. BMC Bioinformatics. 2014;15:78.

32. Kluth M, Runte F, Barow P, Omari J, Abdelaziz ZM, Paustian L, Steurer S, Christina Tsourlakis M, Fisch M, Graefen M, Tennstedt $P$, Huland H, Michl U, Minner S, Sauter G, Simon R, Adam M, Schlomm T. Concurrent deletion of $16 \mathrm{q} 23$ and PTEN is an independent prognostic feature in prostate cancer. Int J Cancer. 2015;137:2354-63.

33. Williams JL, Greer PA, Squire JA. Recurrent copy number alterations in prostate cancer: an in silico meta-analysis of publicly available genomic data. Cancer Genet. 2014:207:474-88.

34. Cher ML, Ito T, Weidner N, Carroll PR, Jensen RH. Mapping of regions of physical deletion on chromosome $16 \mathrm{q}$ in prostate cancer cells by fluorescence in situ hybridization (FISH). J Urol. 1995;153:249-54.

35. Matsuyama H, Pan Y, Yoshihiro S, Kudren D, Naito K, Bergerheim USR, Ekman P. Clinical significance of chromosome 8p, 10q, and 16q deletions in prostate cancer. Prostate. 2003;54:103-11.

36. Cheng Y, Liu W, Kim S-T, Sun J, Lu L, Sun J, Zheng SL, Isaacs WB, Xu J. Evaluation of PPP2R2A as a prostate cancer susceptibility gene: a comprehensive germline and somatic study. Cancer Genet. 2011;204:375-81.

37. He WW, Sciavolino PJ, Wing J, Augustus M, Hudson P, Meissner PS, Curtis RT, Shell BK, Bostwick DG, Tindall DJ, Gelmann EP, Abate-Shen C, Carter KC. A novel human prostate-specific, androgen-regulated homeobox gene (NKX3.1) that maps to 8p21, a region frequently deleted in prostate cancer. Genomics. 1997;43:69-77.

38. Gurel B, Ali TZ, Montgomery EA, Begum S, Hicks J, Goggins M, Eberhart CG, Clark DP, Bieberich CJ, Epstein Jl, De Marzo AM. NKX3.1 as a marker of prostatic origin in metastatic tumors. Am J Surg Pathol. 2010;34:1097-105.

39. Corso G, Carvalho J, Marrelli D, Vindigni C, Carvalho B, Seruca R, Roviello F, Oliveira C. Somatic mutations and deletions of the E-cadherin gene predict poor survival of patients with gastric cancer. J Clin Oncol. 2013;31:868-75. 
40. Watson JEV, Doggett NA, Albertson DG, Andaya A, Chinnaiyan A, van Dekken H, Ginzinger D, Haqq C, James K, Kamkar S, Kowbel D, Pinkel D, Schmitt L, Simko JP, Volik S, Weinberg VK, Paris PL, Collins C. Integration of high-resolution array comparative genomic hybridization analysis of chromosome $16 \mathrm{q}$ with expression array data refines common regions of loss at 16q23-qter and identifies underlying candidate tumor suppressor genes in prostate cancer. Oncogene. 2004;23:3487-94.

41. Fromont $G$, Vallancien $G$, Validire P, Levillain P, Cussenot O. BCAR1 expression in prostate cancer: association with 16q23 LOH status, tumor progression and EGFR/KAl1 staining. Prostate. 2007;67:268-73.

42. Elo JP, Härkönen P, Kyllönen AP, Lukkarinen O, Vihko P. Three independently deleted regions at chromosome arm 16q in human prostate cancer: allelic loss at 16q24.1-q24.2 is associated with aggressive behaviour of the disease, recurrent growth, poor differentiation of the tumour and poor prognosis for the patie. Br J Cancer. 1999;79:156-60.

43. Li J, Yen C, Liaw D, Podsypanina K, Bose S, Wang SI, PuC J, Miliaresis C, Rodgers L, McCombie R, Bigner SH, Giovanella BC, Ittmann M, Tycko B, Hibshoosh H, Wigler MH, Parsons R. PTEN, a putative protein tyrosine phosphatase gene mutated in human brain, breast, and prostate cancer. Science. 1997;275:1943-7.

44. Vlietstra RJ, van Alewijk DCJG, Hermans KGL, van Steenbrugge GJ, Trapman J. Frequent inactivation of PTEN in prostate cancer cell lines and Xenografts. Cancer Res. 1998;58:2720-3.

45. Yamamoto F, Yamamoto M. Scanning copy number and gene expression on the 18q21-qter chromosomal region by the systematic multiplex PCR and reverse transcription-PCR methods. Electrophoresis. 2007;28:1882-95.

46. Fromont G, Godet J, Peyret A, Irani J, Celhay O, Rozet F, Cathelineau X Cussenot O. 8q24 amplification is associated with Myc expression and prostate cancer progression and is an independent predictor of recurrence after radical prostatectomy. Hum Pathol. 2013;44:1617-23.

47. Luo L, McGarvey P, Madhavan S, Kumar R, Gusev Y, Upadhyay G. Distinct lymphocyte antigens 6 (Ly6) family members Ly6D, Ly6E, Ly6K and Ly6H drive tumorigenesis and clinical outcome. Oncotarget. 2016;7(10):11165-93.

48. Shapiro BL. The down syndrome critical region. J Neural Transm Suppl. 1999:57:41-60

49. Filippova GN, Lindblom A, Meincke $\sqcup$, Klenova EM, Neiman PE, Collins SJ, Doggett NA, Lobanenkov W. A widely expressed transcription factor with multiple DNA sequence specificity, CTCF, is localized at chromosome segment 16q22.1 within one of the smallest regions of overlap for common deletions in breast and prostate cancers. Genes Chromosomes Cancer. 1998;22:26-36.

50. Phillips SM, Barton CM, Lee SJ, Morton DG, Wallace DM, Lemoine NR, Neoptolemos JP. Loss of the retinoblastoma susceptibility gene (RB1) is a frequent and early event in prostatic tumorigenesis. Br J Cancer. 1994;70: 1252-7.

51. Aparicio A, Den RB, Knudsen KE. Time to stratify? The retinoblastoma protein in castrate-resistant prostate cancer. Nat Rev Urol. 2011;8:562-8.

52. Taberlay PC, Achinger-Kawecka J, Lun ATL, Buske FA, Sabir K, Gould CM, Zotenko E, Bert SA, Giles KA, Bauer DC, Smyth GK, Stirzaker C, O'Donoghue SI, Clark SJ. Three-dimensional disorganization of the cancer genome occurs coincident with long-range genetic and epigenetic alterations. Genome Res. 2016;26:719-31.

53. Verhagen PCMS, Hermans KGL, Brok MO, van Weerden WM, Tilanus MGJ, de Weger RA, Boon TA, Trapman J. Deletion of chromosomal region 6q14-16 in prostate cancer. Int J Cancer. 2002;102:142-7.

54. Kluth M, Hesse J, Heinl A, Krohn A, Steurer S, Sirma H, Simon R, Mayer P-S, Schumacher U, Grupp K, Izbicki JR, Pantel K, Dikomey E, Korbel JO, Plass C, Sauter G, Schlomm T, Minner S. Genomic deletion of MAP3K7 at 6q12-22 is associated with early PSA recurrence in prostate cancer and absence of TMPRSS2:ERG fusions. Mod Pathol. 2013;26:975-83.

55. Linn DE, Penney KL, Bronson RT, Mucci LA, Li Z, Tomlins S, Rhodes D, Perner S, Dhanasekaran S, Mehra R, Sun X, Kumar-Sinha C, Tomlins S, Chinnaiyan A, Teixeira M, Hermans K, van Marion $R$, van Dekken $H$, Jenster $G$, van Weerden W, Trapman J, Perner S, Demichelis F, Beroukhim R, Schmidt F, Mosquera J, Setlur S, Yoshimoto M, Joshua A, Chilton-Macneill S, et al. Deletion of interstitial genes between TMPRSS2 and ERG promotes prostate cancer progression. Cancer Res. 2016;76:1869-81.

56. Yoshimoto M, Ludkovski O, DeGrace D, Williams JL, Evans A, Sircar K, Bismar TA, Nuin P, Squire JA. PTEN genomic deletions that characterize aggressive prostate cancer originate close to segmental duplications. Genes Chromosomes Cancer. 2012;51:149-60.
57. Hummon AB, Pitt JJ, Camps J, Emons G, Skube SB, Huppi K, Jones TL, Beissbarth T, Kramer F, Grade M, Difilippantonio MJ, Ried T, Caplen NJ. Systems-wide RNAi analysis of CASP8AP2/FLASH shows transcriptional deregulation of the replication-dependent histone genes and extensive effects on the transcriptome of colorectal cancer cells. Mol Cancer. 2012;11:1.

58. Nishizawa M, Kataoka K, Vogt PK. MafA has strong cell transforming ability but is a weak transactivator. Oncogene. 2003;22:7882-90.

59. Feik E, Schweifer N, Baierl A, Sommergruber W, Haslinger C, Hofer P, MajHes A, Madersbacher S, Gsur A. Integrative analysis of prostate cancer aggressiveness. Prostate. 2013;73:1413-26.

60. Maciejowski J, Li Y, Bosco N, Campbell PJ, de Lange T. Chromothripsis and Kataegis induced by telomere crisis. Cell. 2015;163:1641-54.

61. Kass EM, Moynahan ME, Jasin M. When genome maintenance goes badly awry. Mol Cell. 2016;62:777-87.

62. Dawkins HJ, Sellner LN, Turbett GR, Thompson CA, Redmond SL, McNeal JE, Cohen RJ. Distinction between intraductal carcinoma of the prostate (IDCP), high-grade dysplasia (PIN), and invasive prostatic adenocarcinoma, using molecular markers of cancer progression. Prostate. 2000;44:265-70.

63. Bettendorf O, Schmidt H, Staebler A, Grobholz R, Heinecke A, Boecker W, Hertle L, Semjonow A. Chromosomal imbalances, loss of heterozygosity, and immunohistochemical expression of TP53, RB1, and PTEN in intraductal cancer, intraepithelial neoplasia, and invasive adenocarcinoma of the prostate. Genes Chromosomes Cancer. 2008;47:565-72.

64. Qian J, Jenkins RB, Bostwick DG. Detection of chromosomal anomalies and c-myc gene amplification in the cribriform pattern of prostatic intraepithelial neoplasia and carcinoma by fluorescence in situ hybridization. Mod Pathol. 1997;10:1113-9.

65. Mao X, Yu Y, Boyd LK, Ren G, Lin D, Chaplin T, Kudahetti SC, Stankiewicz E, Xue L, Beltran L, Gupta M, Oliver RTD, Lemoine NR, Berney DM, Young BD, $Y-J$ L. Distinct genomic alterations in prostate cancers in Chinese and western populations suggest alternative pathways of prostate carcinogenesis. Cancer Res. 2010;70:5207-12.

66. Kan Z, Jaiswal BS, Stinson J, Janakiraman V, Bhatt D, Stern HM, Yue P, Haverty PM, Bourgon R, Zheng J, Moorhead M, Chaudhuri S, Tomsho LP, Peters BA, Pujara K, Cordes S, Davis DP, Carlton VEH, Yuan W, Li L, Wang W, Eigenbrot C, Kaminker JS, Eberhard DA, Waring P, Schuster SC, Modrusan Z, Zhang Z, Stokoe D, de Sauvage FJ, et al. Diverse somatic mutation patterns and pathway alterations in human cancers. Nature. 2010;466:869-73.

67. Grasso CS, Y-M W, Robinson DR, Cao X, Dhanasekaran SM, Khan AP, Quist MJ, Jing X, Lonigro RJ, Brenner JC, Asangani IA, Ateeq B, Chun SY, Siddiqui J, Sam L, Anstett M, Mehra R, Prensner JR, Palanisamy N, Ryslik GA, Vandin F, Raphael BJ, Kunju LP, Rhodes DR, Pienta KJ, Chinnaiyan AM, Tomlins SA. The mutational landscape of lethal castration-resistant prostate cancer. Nature. 2012:487:239-43.

68. Castro P, Creighton CJ, Ozen M, Berel D, Mims MP, Ittmann M. Genomic profiling of prostate cancers from African American men. Neoplasia. 2009; 11:305-12.

69. Huang S, Gulzar ZG, Salari K, Lapointe J, Brooks JD, Pollack JR. Recurrent deletion of CHD1 in prostate cancer with relevance to cell invasiveness. Oncogene. 2012;31:4164-70.

70. Friedlander TW, Roy R, Tomlins SA, Ngo VT, Kobayashi Y, Azameera A, Rubin MA, Pienta KJ, Chinnaiyan A, Ittmann MM, Ryan CJ, Paris PL. Common structural and epigenetic changes in the genome of castration-resistant prostate cancer. Cancer Res. 2012;72:616-25.

71. Vainio $P$, Wolf M, Edgren $H, H e T$, Kohonen P, Mpindi J-P, Smit F, Verhaegh G, Schalken J, Perälä M, Iljin K, Kallioniemi O. Integrative genomic, transcriptomic, and RNAi analysis indicates a potential oncogenic role for FAM110B in castration-resistant prostate cancer. Prostate. 2012;72:789-802.

72. Chua MLK, Lo W, Pintilie M, Murgic J, Lalonde E, Bhandari V, Mahamud O, Gopalan A, Kweldam CF, van Leenders GJLH, Verhoef El, Hoogland AM, Livingstone J, Berlin A, Dal Pra A, Meng A, Zhang J, Orain M, Picard V, Hovington H, Bergeron A, Lacombe L, Fradet Y, Têtu B, Reuter VE, Fleshner N, Fraser M, Boutros PC, van der Kwast TH, Bristow RG, Prostate Cancer A. "Nimbosus": genomic instability and SChLAP1 Dysregulation underpin aggression of Intraductal and Cribriform subpathologies. Eur Urol. 2017;72:665-74.

73. Prensner JR, lyer MK, Sahu A, Asangani IA, Cao Q, Patel L, Vergara IA, Davicioni E, Erho N, Ghadessi M, Jenkins RB, Triche TJ, Malik R, Bedenis R, McGregor N, Ma T, Chen W, Han S, Jing X, Cao X, Wang X, Chandler B, Yan W, Siddiqui J, Kunju LP, Dhanasekaran SM, Pienta KJ, Feng FY, Chinnaiyan AM. The long noncoding RNA SChLAP1 promotes aggressive prostate cancer and antagonizes the SWI/SNF complex. Nat Genet. 2013;45:1392-8. 
74. Mehra R, Udager AM, Ahearn TU, Cao X, Feng FY, Loda M, Petimar JS, Kantoff P, Mucci LA, Chinnaiyan AM. Overexpression of the long non-coding RNA SChLAP1 independently predicts lethal prostate cancer. Eur Urol. 2016; 70:549-52.

75. Böttcher R, Hoogland AM, Dits N, Verhoef El, Kweldam C, Waranecki P, Bangma $\mathrm{CH}$, van Leenders $\mathrm{GJ} L \mathrm{H}$, Jenster $\mathrm{G}$. Novel long non-coding RNAs are specific diagnostic and prognostic markers for prostate cancer. Oncotarget. 2015;6:4036-50.

Submit your next manuscript to BioMed Central and we will help you at every step:

- We accept pre-submission inquiries

- Our selector tool helps you to find the most relevant journal

- We provide round the clock customer support

- Convenient online submission

- Thorough peer review

- Inclusion in PubMed and all major indexing services

- Maximum visibility for your research

Submit your manuscript at www.biomedcentral.com/submit
Biomed Central 